\title{
Using Perls Staining to Trace the Iron Uptake Pathway in Leaves of a Prunus Rootstock Treated with Iron Foliar Fertilizers
}

\author{
Juan J. Rios, Sandra Carrasco-Gil, Anunciación Abadía and Javier Abadía*
}

Department of Plant Nutrition, Aula Dei Experimental Station, Consejo Superior de Investigaciones Científicas, Zaragoza, Spain

The aim of this study was to trace the Fe uptake pathway in leaves of Prunus rootstock (GF 677; Prunus dulcis $\times$ Prunus persica) plants treated with foliar Fe compounds using the Perls blue method, which detects labile Fe pools. Young expanded leaves of Fedeficient plants grown in nutrient solution were treated with Fe-compounds using a brush. Iron compounds used were the ferrous salt $\mathrm{FeSO}_{4}$, the ferric salts $\mathrm{Fe}_{2}\left(\mathrm{SO}_{4}\right)_{3}$ and $\mathrm{FeCl}_{3}$, and the chelate $\mathrm{Fe}(\mathrm{III})$-EDTA, all of them at concentrations of $9 \mathrm{mM} \mathrm{Fe}$. Leaf $\mathrm{Fe}$ concentration increases were measured at 30, 60, $90 \mathrm{~min}$, and $24 \mathrm{~h}$, and $70 \mu \mathrm{m}$-thick

OPEN ACCESS

Edited by: Patrick Brown,

University of California, Davis, USA

Reviewed by: Victoria Fernandez, Technical University of Madrid, Spain Ümit Barlș Kutman, Konya Food and Agriculture University, Turkey

*Correspondence:

Javier Abadía

jabadia@eead.csic.es

Specialty section: This article was submitted to Plant Nutrition a section of the journal Frontiers in Plant Science

Received: 30 March 2016 Accepted: 06 June 2016

Published: 27 June 2016

Citation:

Rios JJ, Carrasco-Gil S, Abadía A and Abadía J (2016) Using Perls Staining to Trace the Iron Uptake Pathway in Leaves of a Prunus Rootstock Treated with Iron Foliar Fertilizers. Front. Plant Sci. 7:893. doi: 10.3389/fp/s.2016.00893 leaf transversal sections were obtained with a vibrating microtome and stained with Perls blue. In vitro results show that the Perls blue method is a good tool to trace the Fe uptake pathway in leaves when using Fe salts, but is not sensitive enough when using synthetic $\mathrm{Fe}$ (III)-chelates such as Fe(III)-EDTA and Fe(III)-IDHA. Foliar Fe fertilization increased leaf Fe concentrations with all Fe compounds used, with inorganic Fe salts causing larger leaf Fe concentration increases than Fe(III)-EDTA. Results show that Perls blue stain appeared within 30 min in the stomatal areas, indicating that Fe applied as inorganic salts was taken up rapidly via stomata. In the case of using $\mathrm{FeSO}_{4}$ a progression of the stain was seen with time toward vascular areas in the leaf blade and the central vein, whereas in the case of $\mathrm{Fe}(\mathrm{III})$ salts the stain mainly remained in the stomatal areas. Perls stain was never observed in the mesophyll areas, possibly due to the low concentration of labile Fe pools.

Keywords: Prunus dulcis x P. persica, Fe plant nutrition, foliar Fe fertilization, leaf Fe localisation, Perls blue staining

\section{INTRODUCTION}

Iron deficiency is a limiting factor for food production in many areas of the world, affecting agricultural produce quality and yield in horticultural and fruit tree crops (Abadía et al., 2011; Briat et al., 2015). Species affected include grapevine, citrus, pear and peach trees and others. In Fedeficient plants leaves become yellow because the synthesis and assembly of thylakoid components are impaired (Terry and Abadía, 1986).

Different agricultural management strategies are used to control Fe chlorosis in tree crops, with the most common one being the soil application of soluble Fe(III)-chelates (El-Jendoubi et al., 2011). Other current practices include the injection of Fe compounds in liquid or solid forms 
into tree branches (Larbi et al., 2003), as well as the application of fertilizers to the plant foliage, the so-called foliar fertilization (Fernández et al., 2013). Foliar fertilization is cheaper than soil fertilization, although the effectiveness of the technique may, in some cases, be insufficient to correct Fe deficiency (El-Jendoubi et al., 2014). Both inorganic- and organic-based Fe compounds are currently used in foliar fertilization (Abadía et al., 2011; Fernández et al., 2013). Until now, foliar Fe fertilization studies have been focused on testing which Fe formulations have a better efficiency (e.g., Fe oxidation states, ions vs. chelates, $\mathrm{pH}$, surfactants and adjuvants, etc.; Rombolà et al., 2000; Abadía et al., 2002; Álvarez-Fernández et al., 2004; Fernández and Ebert, 2005; Schönherr et al., 2005; Fernández et al., 2006; Fernández and Eichert, 2009; Borowski, 2013), understanding the Fe uptake pathway in the leaf and investigating whether environmental conditions could affect Fe uptake from fertilizers (Eichert and Burkhardt, 2001; Schönherr, 2001; Schönherr and Luber, 2001; Schlegel and Schönherr, 2002; Schönherr and Schreiber, 2004; Fernández and Ebert, 2005; Schönherr et al., 2005).

Many foliar fertilization studies have compared Fe chemical forms. Early studies provided conflicting data, since some of them indicated that $\mathrm{FeSO}_{4}$ had better entrance rates than Fe(III)-EDDHA (Kannan, 1969), whereas others observed that chelates were faster than inorganic Fe regarding penetration and translocation (Basiouny and Biggs, 1976). Recent foliar fertilization studies with Fe-deficient pear trees, including surface-active agents, indicated that $\mathrm{FeSO}_{4}$ had a similar regreening effect to that of Fe(III)-DTPA (Álvarez-Fernández et al., 2004). In peach trees treated with different Fe-compounds, the best regreening results were with $\mathrm{FeSO}_{4}$, followed by those with $\mathrm{Fe}$ (III)-citrate and Fe(III)-EDTA (Álvarez-Fernández et al., 2004).

Environmental conditions, including temperature, relative humidity (RH) and light, could affect leaf Fe uptake (Ramsey et al., 2005). Temperature could influence chemical reactions and physical proprieties of plants from the cellular to the whole plant level (Gruda, 2005) and moderately high temperatures could stimulate photosynthesis, transpiration and penetration rates, although the permeability of isolated leaf cuticles to salts was shown to be unaffected by temperature (Schönherr and Luber, 2001; Schönherr, 2002). Also, light affects many leaf physiological processes such as stomatal opening, photosynthesis and xylem flux. Open stomata could increase foliar uptake (Outlaw, 2003) and this has been described as a major factor for foliar penetration through the abaxial leaf side (Greenne and Bukovac, 1971; Schlegel et al., 2006). Another key factor is $\mathrm{RH}$, which could influence many processes, including the hydration of leaf cuticles, which decrease with decreasing RH (Chamel et al., 1991, 1992; Schönherr, 2000), as well as the applied fertilizer drying time and/or deliquescence on the leaf surface (the point of deliquescence, POD, is defined as the $\mathrm{RH}$ value when the compound becomes a solute; Fernández et al., 2008; Fernández and Eichert, 2009). Many studies on foliar fertilization were carried out under $100 \%$ RH to simplify the system (Schönherr and Luber, 2001; Schönherr and Schreiber, 2004; Eichert and Goldbach, 2008), although such $\mathrm{RH}$ values are rarely found -even at night- under field conditions in agricultural areas affected by $\mathrm{Fe}$ deficiency.

Leaves have a protecting cuticle that limits the transport of water and ions, not only at its outer surface, composed of cutin and waxes (Schönherr and Riederer, 1986; Schönherr and Schreiber, 2004), but also possibly due to its internal structure and composition (Fernández et al., 2016). The cuticle minimizes passive water loss and avoids leaching of apoplastic solutes. It has been suggested that hydrophilic compounds (including $\mathrm{Fe}$ ) may be taken up by leaves through cuticle cracks, stomata, leaf hairs and perhaps through specialized epidermal cells (Fernández and Brown, 2013), and it is known that physical damage of the leaf surface could aid penetration (Jordan and Brodribb, 2007; Munné-Bosch, 2007). It has been also hypothesized that hydrophilic solutes could penetrate cuticles by a pathway different than that used by hydrophobic solutes, following the so-called "polar pores" or "aqueous pores", generated by the adsorption of water to polar moieties located in the cuticle (Schönherr, 2000; Schönherr and Schreiber, 2004); however, these pores have not been visualized so far (Koch and Ensikat, 2008).

Uptake of pure water solutions through stomata was considered unlikely by Schönherr and Bukovac (1972), but further studies indicated that condensation water on the pore walls may facilitate stomatal uptake (Eiden et al., 1994; Burkhardt et al., 1999), and that uptake via stomata could occur not only for large anions such as uranine but also for small cations such as Fe(III) (Eichert and Burkhardt, 2001). Image studies were carried out using different techniques, including fluorescent dyes. Whereas Strugger (1939) indicated that the dye was visible inside stomata, and Dybing and Currier (1961) showed that an anionic fluorescent dye entered leaves via stomata, Schönherr and Bukovac (1978) and Schönherr (2006) indicated that cuticular ledges were preferential points, perhaps having a higher permeability, for penetration of solutes accumulated in vicinity of guard cells. The role of stomata in foliar uptake was also supported by the enhanced uptake of fluorescein in leaves when stomata were open (Eichert et al., 1998). Also, Eichert and Burkhardt (2001) and Eichert et al. (2008) have suggested the occurrence of active and inactive stomata in terms of cuticle wettability around guard cells and solute uptake.

The Perls Prussian blue stain, widely used to detect labile $\mathrm{Fe}$ in biological tissues by forming a precipitate with a formula $\mathrm{Fe}_{4}\left[\mathrm{Fe}(\mathrm{CN})_{6}\right]_{3} \times \mathrm{H}_{2} \mathrm{O}$ [the corresponding IUPAC name is Iron(II,III) hexacyanoferrate(II,III)], has been applied only recently to plant research, due to poor penetration and sensitivity in hydrophobic tissues. Whereas the Perls method has been reported to stain $\mathrm{Fe}$ at concentrations of $35 \mu \mathrm{M}$ from both $\mathrm{Fe}$ (II) and Fe(III) (Roschzttardtz et al., 2009), a new protocol, with an additional step including diaminobenzidine, was designed to enhance sensitivity (Roschzttardtz et al., 2009, 2010). This was later applied to leaves treated with Fe foliar fertilizers (ElJendoubi et al., 2014).

In summary, in spite of the many studies carried out on foliar fertilization, the knowledge on the Fe uptake pathways in leaves is still poorly known. The aim of this study was to investigate how Fe applied to the leaf surface in different chemical forms enters 
the leaves of a Prunus species, using Perls staining, a technique capable to detect labile Fe pools. The rootstock GF677 was used as a Prunus model because of the commercial agricultural interest and the easiness in getting adequate plant material.

\section{MATERIALS AND METHODS}

\section{Plant Growth Conditions and Sampling}

Micropropagated, clonal GF 677 rootstock plants [Prunus dulcis (Mill.) D.A. Webb $\times$ Prunus persica (L.) Batsch] were acquired from Agromillora Catalana S.A. (Subirats, Barcelona, Spain). Plants were grown for 2 weeks in $300 \mathrm{~mL}$ pots on a peat substrate. Plants were transferred for 2 days to $15 \mathrm{~L}$ plastic boxes (31 plants per box) filled with Hoagland's nutrient solution diluted 10 -fold. Then, plants were grown in continuously aerated, halfstrength Hoagland nutrient solution $\mathrm{pH} 5.5$, containing (in $\mathrm{mM}$ ) $2.5 \mathrm{Ca}\left(\mathrm{NO}_{3}\right)_{2}, 2.5 \mathrm{KNO}_{3}, 1 \mathrm{MgSO}_{4}, 1 \mathrm{KH}_{2} \mathrm{PO}_{4}$, and (in $\left.\mu \mathrm{M}\right) 46.2$ $\mathrm{H}_{3} \mathrm{BO}_{3}, 9.2 \mathrm{MnCl}_{2}, 0.38 \mathrm{CuSO}_{4}, 2.4 \mathrm{ZnSO}_{4}, 0.12 \mathrm{Na}_{2} \mathrm{MoO}_{4}$, and $90 \mu \mathrm{M}$ Fe(III)-EDTA. Plants were grown in a growth chamber (Fitoclima $10000 \mathrm{EHHF}$, Aralab, Albarraque, Portugal) with a photoperiod of $16 \mathrm{~h}$ light (with a PPFD of $350 \mu \mathrm{mol}$ photon $\mathrm{m}^{-2} \mathrm{~s}^{-1} \mathrm{PAR}$ at the leaf level) at $23^{\circ} \mathrm{C} / 8 \mathrm{~h}$ of darkness at $20^{\circ} \mathrm{C}$, and constant $70 \% \mathrm{RH}$. Nutrient solutions were renewed every week. After 2 weeks of growth, when roots were approximately $10 \mathrm{~cm}$ long (with 5-6 leaves), plants were transferred to $2 \mathrm{~L}$ pots (four plants per pot) filled with half-strength Hoagland nutrient solution, $\mathrm{pH} 5.5$, containing $0 \mu \mathrm{M}[-\mathrm{Fe}]$ or $90 \mu \mathrm{M}$ Fe(III)EDTA $[+\mathrm{Fe}]$. Subsequently, nutrient solutions were renewed every week. Iron deficiency symptoms (leaf chlorosis) appeared progressively in young leaves.

Treatments were applied to leaves of plants grown under $\mathrm{Fe}$ deficiency conditions for approximately 2 weeks, when plants had approximately 11 leaves (Figure 1). Foliar fertilization was carried out in expanded Fe-deficient leaves with a SPAD reading of approximately 10-20 (green, Fe-sufficient leaves had at this stage SPAD values of approximately 35). Plants were treated with foliar fertilizers approximately $2 \mathrm{~h}$ after the onset of the light period in the growth chamber. Many preliminary experiments were carried out to explore the possibility of detecting $\mathrm{Fe}$ with Perls, and it was observed that a darkpretreatment led to the best results. Therefore, the standard protocol included covering plants with a black plastic bag overnight, with the bag being removed only $30 \mathrm{~min}$ before foliar application. In the case of $\mathrm{FeSO}_{4}$, the treatment was also applied without this dark pre-treatment, i.e., in plants illuminated by the growth chamber light for $2 \mathrm{~h}$. Four different fertilizer solutions containing $9 \mathrm{mM}$ Fe were used. The experiment used a completely randomized design with three replications. The solutions contained: (i) the $\mathrm{Fe}$ (II) salt $\mathrm{FeSO}_{4}$; (iii) the $\mathrm{Fe}$ (III) salt $\mathrm{Fe}_{2}\left(\mathrm{SO}_{4}\right)_{3}$; (iv) the $\mathrm{Fe}$ (III) salt $\mathrm{FeCl}_{3}$, and (ii) the chelate Fe(III)-EDTA; all solutions contained $0.2 \%$ of a non-ionic, organo-silicon surfactant (Break-Thru S 233, Evonik Industries AG, Essen, Germany). The products used were $\mathrm{FeSO}_{4} \cdot 7 \mathrm{H}_{2} \mathrm{O}$ (CAS Number 7782-63-0; Sigma-Aldrich), $\mathrm{Fe}_{2}\left(\mathrm{SO}_{4}\right)_{3} \cdot \mathrm{xH}_{2} \mathrm{O}$ (CAS Number 15244-10-7), and $\mathrm{FeCl}_{3} \cdot 6 \mathrm{H}_{2} \mathrm{O}$ (CAS Number 10025-77-1).

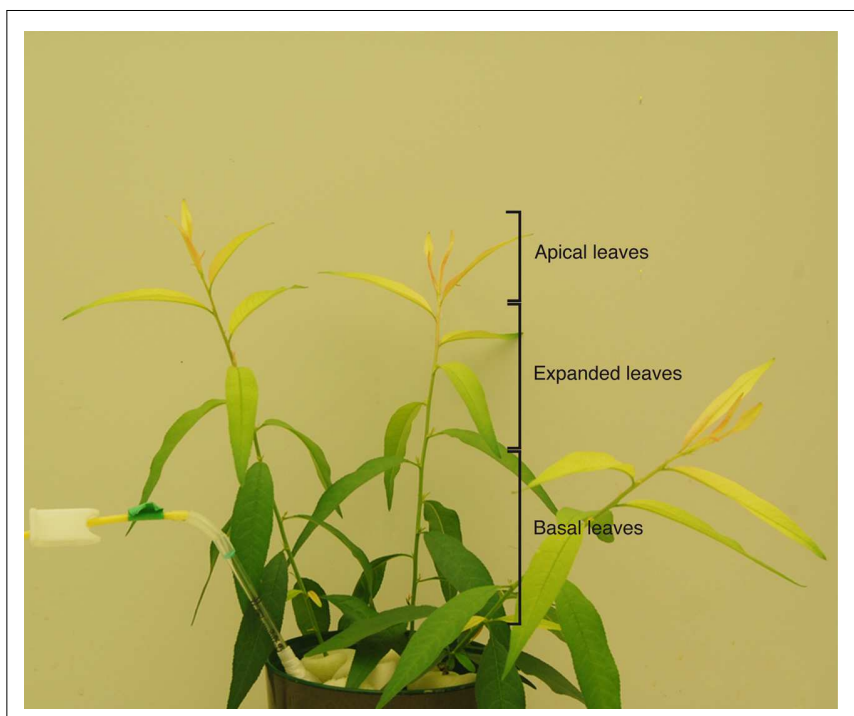

FIGURE 1 | Prunus dulcis $\times$ P persica plants grown in nutrient solution under Fe deficiency for $\mathbf{1 5}$ days. Iron-deficiency symptoms include leaf chlorosis. Expanded leaves were those selected to be treated with the Fe foliar fertilizers.

The $\mathrm{pH}$ values after adding the surfactant were 3.9, 3.3, 3.2, and 4.1 in the cases of $\mathrm{FeSO}_{4}, \mathrm{Fe}_{2}\left(\mathrm{SO}_{4}\right)_{3}, \mathrm{FeCl}_{3}$, and $\mathrm{Fe}$ (III)EDTA, respectively, and no further $\mathrm{pH}$ adjustments were made to comply with the normal grower's practices. A similar $\mathrm{pH}$ value, 4.0, has been used for of $\mathrm{FeSO}_{4}$ in previous studies (Fernández et al., 2008; El-Jendoubi et al., 2014). The fertilizer was applied only to the abaxial side of five fully expanded Fe-deficient leaves in each plant using a paintbrush (in this plant species stomata are only present in the abaxial side). The procedure was repeated three times, with the full fertilization process lasting approximately five min. The total volume of foliar fertilizer (the sum of the three applications) was approximately $700 \mu \mathrm{L}$ per plant. To test the role of stomata, the nutrient solution of one pot was supplemented with $100 \mu \mathrm{M}$ ABA (from stock dissolved in methanol) $24 \mathrm{~h}$ before foliar fertilization. Leaf samples were taken for mineral and microscopic analysis at four different times after the first foliar fertilizer application: 30, 60, and $90 \mathrm{~min}$ and $24 \mathrm{~h}$.

\section{Analysis of Micronutrient Concentrations}

Leaves (fertilized and untreated controls) were washed thoroughly twice with ultrapure water Type I. Leaves were dried in an oven at $60^{\circ} \mathrm{C}$, ground in a $\mathrm{ZrO}_{2}$ ball mill (MM301, Retsch, Haan, Germany) and stored at room temperature until analysis. Plant samples (200 mg DW of tissue) were digested using a microwave system (Milestone Ethos Plus, Bergamo, Italy) with $6.4 \mathrm{~mL} \mathrm{HNO}_{3}$ (26\%, TraceSelect Ultra, Sigma-Aldrich) and $1.6 \mathrm{~mL} \mathrm{H}_{2} \mathrm{O}_{2}(30 \%)$. The microwave digestion program was $5 \mathrm{~min}$ at $100^{\circ} \mathrm{C}, 10 \mathrm{~min}$ at $170^{\circ} \mathrm{C}$, and $35 \mathrm{~min}$ at $180^{\circ} \mathrm{C}$. The digest was filtered through a $0.45 \mu \mathrm{m}$ PTFE filter, diluted to $10 \mathrm{~mL}$ in water Type $\mathrm{I}$, and metals ( $\mathrm{Fe}, \mathrm{Mn}, \mathrm{Cu}$, and $\mathrm{Zn}$ ) determined by flame atomic absorption spectrometry (FAAS) 
using a Solaar 969 apparatus (Unicam Ltd, Cambridge, UK). Three replications per treatment and batch were analyzed. Total micronutrient contents in leaves were obtained from the leaf concentrations and DW values. Iron concentration data were analyzed using two-way ANOVA and means compared (Fisher's LSD test at $p<0.05$ ) using Genstat.

\section{Leaf Structure Staining}

Leaves were first washed twice with water Type I, and then blotted dry with filter paper. Leaf pieces $\left(2 \mathrm{~cm}^{2}\right)$ from the middle of the leaf blade were embedded in 5\% agar and transversal leaf crosssections (70 $\mu \mathrm{m}$-thick) were obtained using a vibrating blade microtome (VT1000 S, Leica Microsystems GmbH, Wetzlar, Germany). Leaf sections were stained either with safranin only (for lignin) or first with safranin and then with Alcian blue (for pectins). For safranin staining, fresh cross-sections were incubated with $0.01 \%(\mathrm{w} / \mathrm{v})$ safranin for $1 \mathrm{~min}$ and washed three times with water Type I. After washing, some safranin-stained sections were also incubated for approximately 30 s with $50 \%$ diluted Alcian blue (1 g Alcian blue and $3 \mathrm{~mL}$ of glacial acetic acid in $10 \mathrm{~mL}$ water), and then washed three times with water Type I. Bright light images $(2592 \times 1994$ pixels $)$ were acquired with an inverted microscope (DM IL LED, Leica) fitted with a charge-coupled device (CCD) camera (Leica DFC 240C).

\section{Perls Iron Staining of Transversal Leaf Sections}

The limits of detection of the Perls blue staining technique were assessed for the different compounds used as foliar fertilizers using porcelain spot plates. Tests included the compounds [ $\mathrm{FeSO}_{4}, \mathrm{Fe}_{2}\left(\mathrm{SO}_{4}\right)_{3}, \mathrm{FeCl}_{3}$, and $\mathrm{Fe}(\mathrm{III})$-EDTA] in concentrations ranging from $5 \mu \mathrm{M}$ to $9 \mathrm{mM}$ Fe. The complexes of Fe with nicotianamine (NA), Fe(III)-NA, and Fe(II)-NA, as well as $\mathrm{Fe}(\mathrm{III})$-citrate, were also assayed at the same concentrations. All samples $(200 \mu \mathrm{L})$ were placed in plate wells, $20 \mu \mathrm{L}$ of Perls dye (in $2 \% \mathrm{HCL}$ ) was added and mixed, and the blue color was developed for $20 \mathrm{~min}$.

For leaf section Perls staining, leaves were excised, washed twice with water Type I and blotted dry with filter paper. Then, leaf pieces $\left(2 \mathrm{~cm}^{2}\right)$ from the middle of the leaf were embedded in 5\% agar (Sigma-Aldrich, St Louis, Mo, USA) and transversal sections (70 $\mu \mathrm{m}$-thick) were obtained using a vibrating blade microtome (VT1000 S, Leica, Germany). Fresh sections were incubated with a $2 \% \mathrm{~K}_{4}\left[\mathrm{Fe}(\mathrm{CN})_{6}\right], 2 \% \mathrm{HCl}$ solution for $30 \mathrm{~min}$ at room temperature. Negative stain controls were run by incubating fresh sections with $\mathrm{HCl}$. Finally, sections were washed three times with water Type I reagent grade and bright light images $(2592 \times 1994$ pixels $)$ were taken as indicated above. Chlorophyll fluorescence images were taken with the same microscope, using an "A" Leica filter cube (excitation and emission filters BP 340-380 and LP 425, respectively).

\section{RESULTS}

Iron deficiency symptoms (leaf chlorosis) appeared progressively in young leaves after imposing the Fe-deficiency conditions. After 2 weeks of growth with zero Fe, plants showed marked chlorosis symptoms (Figure 1). Then, foliar fertilization was carried out in young, expanded Fe-deficient leaves showing chlorosis symptoms (middle leaves in Figure 1).

\section{Effects of Fe Foliar Fertilization on Leaf Fe Concentration}

In all cases, treated leaves were washed thoroughly with water Type I before analysis to remove Fe remaining on the leaf surface, so that the mineral analyses reflect constitutive $\mathrm{Fe}$ plus any Fe from the foliar fertilizer incorporated into the leaf (e.g., incorporated in cells and/or in other leaf structures). The total $\mathrm{Fe}$ concentration in the leaves of Fe-deficient plants was approximately $17 \mu \mathrm{g} \mathrm{g}^{-1} \mathrm{DW}$ at the beginning of the experiment (Table 1). All Fe foliar fertilization treatments increased markedly the leaf Fe concentrations, with the only exception of those plants treated with ABA, where the Fe concentrations did not change from the initial values (Table 1).

Thirty min after Fe foliar application, the leaf Fe concentration had increased two to threefold when compared to the untreated Fe-deficient leaves (Table 1). Iron concentrations at this time were in the range from 35 to $56 \mu \mathrm{g} \mathrm{g}^{-1} \mathrm{DW}$, with Fe(III)-EDTA and $\mathrm{FeCl}_{3}$ leading to the highest values and $\mathrm{FeSO}_{4}$ and $\mathrm{Fe}_{2}\left(\mathrm{SO}_{4}\right)_{3}$ to the lowest ones. In the case of $\mathrm{FeSO}_{4}, \mathrm{Fe}$ concentrations were

TABLE 1 | Iron concentration in leaves of Prunus dulcis $\times$ P. persica foliar fertilized with different Fe compounds.

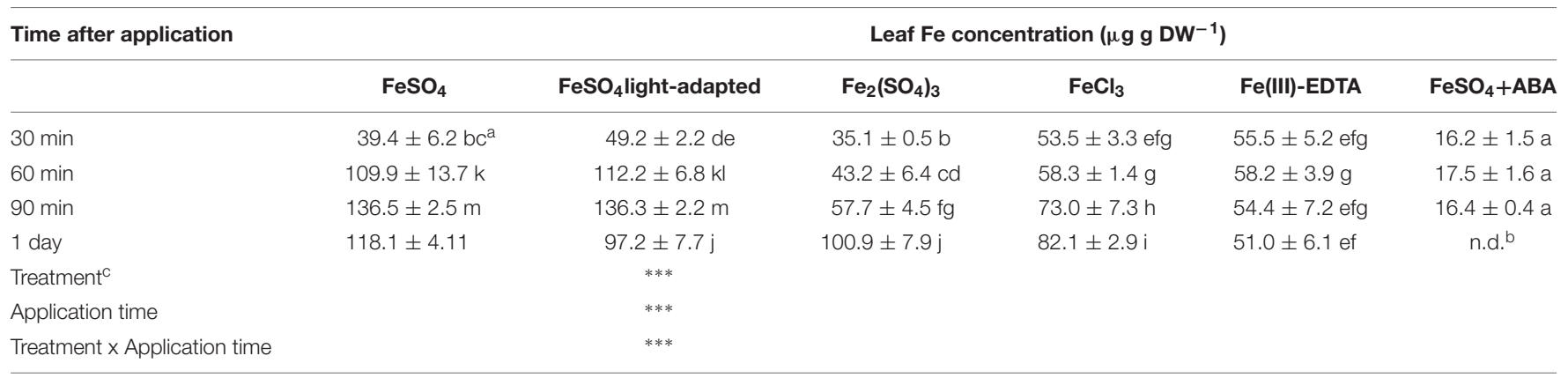

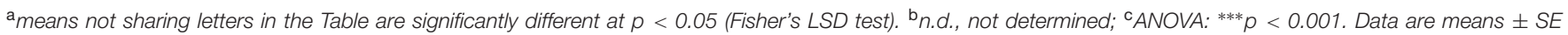

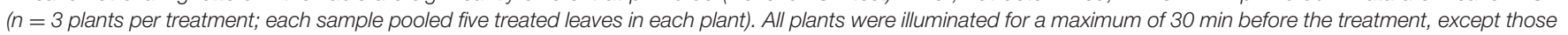
in column 2, which were light-adapted for $2 \mathrm{~h}$ before the treatment. The initial Fe concentration was $16.8 \pm 1.5 \mu \mathrm{g} \mathrm{D} \mathrm{W}^{-1}(\mathrm{n}=3$ ). 
significantly higher when the dark pre-treatment was absent. Thirty min later (60 min after fertilizer application), leaf Fe concentrations had increased more than twofold in the case of $\mathrm{FeSO}_{4}$ (up to $112 \mu \mathrm{g} \mathrm{Fe} \mathrm{g}{ }^{-1} \mathrm{DW}$ ), whereas increases were minor in the case of $\mathrm{Fe}$ (III) salts and the Fe concentration did not change in the case of Fe(III)-EDTA. After 30 min more (90 min after fertilizer application), additional increases in leaf Fe concentrations occurred for most of the Fe compounds, with the exception of leaves treated with Fe(III)-EDTA, where the Fe concentration did not change. At this time, $\mathrm{FeSO}_{4}$ had led to the

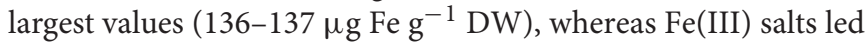
to values lower than $75 \mu \mathrm{g} \mathrm{Fe} \mathrm{g}^{-1} \mathrm{DW}$ (Table 1). One day after Fe application, the leaf Fe concentration had decreased somewhat for $\mathrm{FeSO}_{4}$, with the decrease being larger for plants without a dark pre-treatment, whereas $\mathrm{Fe}$ (III) salts led to further increases in leaf Fe concentrations, with the increase being larger in the case of the sulfate than the chloride form, whereas no change was found for Fe(III)-EDTA (Table 1).

\section{Localization of Xylem and Phloem Tissues in Leaf Cross-sections}

In order to localize zones corresponding to the xylem and phloem, which are rich in lignins and pectins, respectively, we used safranin and Alcian blue stains in fresh leaf sections (Figure 2). Safranin provides a red color and labels structures that are rich in lignins, whereas Alcian blue stains structures rich in pectins. Both in the case of the main veins (Figures $2 \mathbf{A}, \mathbf{B}, \mathbf{E}, \mathbf{F}$ ) and secondary ones (Figures 2C,D,G,H), an inner zone markedly stained with safranin was assigned to xylem tissue (marked with $\mathrm{X}$ in all Figures), whereas a zone surrounding the abaxial side of the xylem markedly stained with Alcian blue was assigned to phloem tissue (marked with P in all Figures). Mesophyll (M; in green due to the chlorophyll) tissue areas are also marked in the Figures.

\section{Assessment of Perls Staining Sensitivity}

The Perls Prussian blue has been reported to detect in plant tissues $35 \mu \mathrm{M} \mathrm{Fe}$, irrespective of the $\mathrm{Fe}$ oxidation state (Roschzttardtz et al., 2009). The limits of detection for the Perls blue staining were different for the different $\mathrm{Fe}$ compounds used. In the case of the three $\mathrm{Fe}$ inorganic salts used $\left[\mathrm{FeSO}_{4}\right.$, $\mathrm{Fe}_{2}\left(\mathrm{SO}_{4}\right)_{3}$, and $\left.\mathrm{FeCl}_{3}\right]$ the blue stain was visible down to $\mathrm{Fe}$ concentrations of $5 \mu \mathrm{M}$ (Figure 3 ). This blue precipitate is due to the formation of insoluble Iron(II,III) hexacyanoferrate(II,III). However, in the case of Fe(III)-EDTA and Fe(III)-IDHA the blue stain was scarcely visible at a Fe concentration of $100 \mu \mathrm{M}$. This may be ascribed to the precipitation of only a small fraction of the total Fe as Iron(II,III) hexacyanoferrate(II,III), with most of the Fe being still chelated by the chelating agent. To assess the possible detection of natural Fe chelates, Fe-NA complexes and Fe-citrate were also assayed, and the limits of detection for the Perls blue staining were lower than $25 \mu \mathrm{M}$ Fe for Fe(II)-NA, $\mathrm{Fe}(\mathrm{III})-\mathrm{NA}$, and Fe-citrate (Figure 3).

\section{Perls Staining of Tissue Sections}

Leaf cross-sections were observed after Perls staining by optical microscopy. The adaxial and abaxial epidermis (AE and $\mathrm{AbE}$, respectively), pallisade and spongy mesophyll (PM and SM, respectively), stomata (St), and the stomatal cavity and guard cells (SC and GC, respectively) are labeled in Figures 4-7.

The Perls blue precipitate Fe staining was observed in some cases but only in two zones, the stomatal and vascular areas, and this was dependent on the Fe compound used and also on the

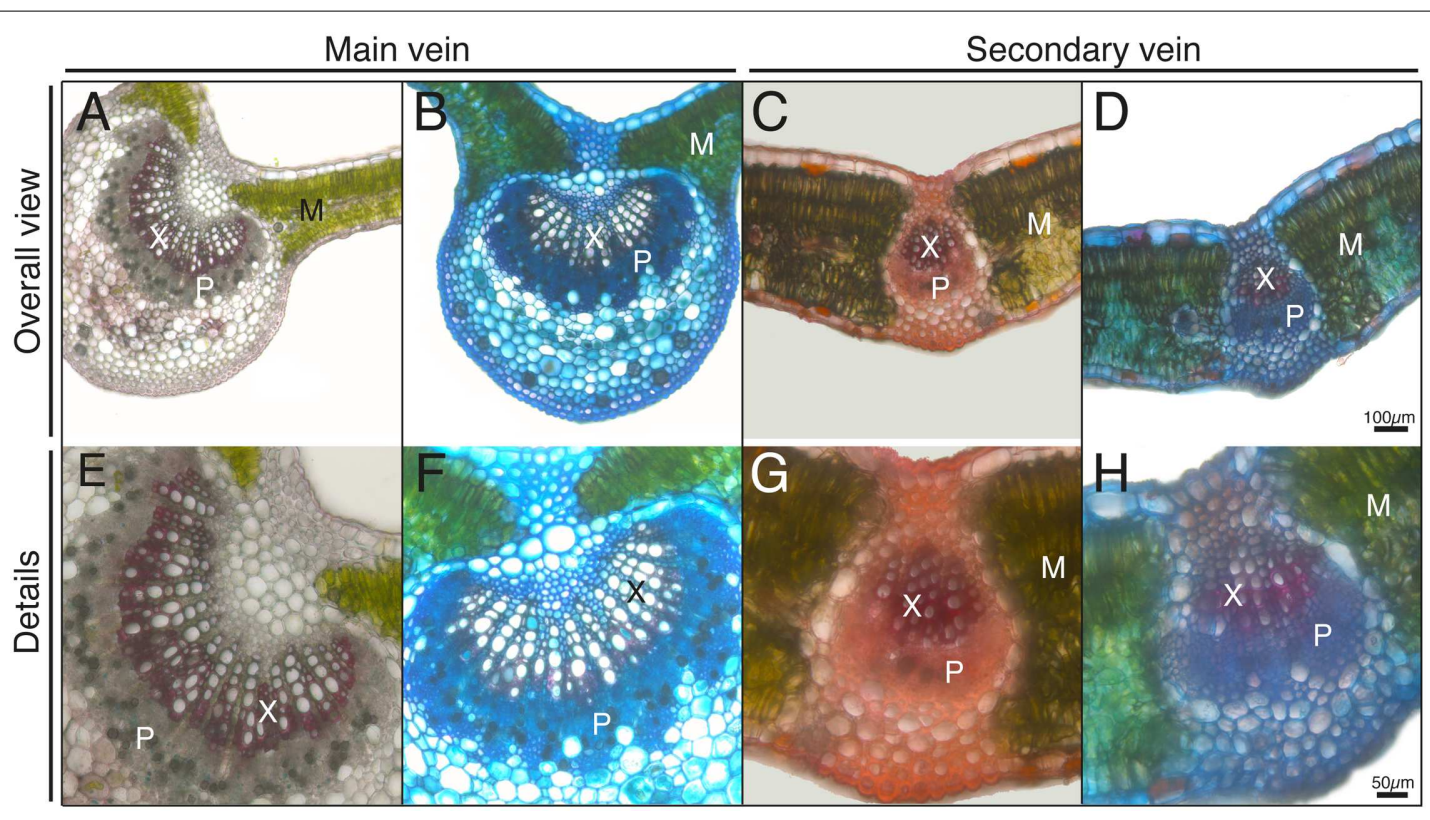

FIGURE 2 | Histological staining from transversal leaf sections. Sections were incubated with safranin (A,C,E,G) or safranin + alcian blue (B,D,F,H). Lignin structures are stained in red and cell walls in blue. Phloem and xylem tissues ( $P$ and $X$, respectively) and mesophyll tissue (M) are marked in the Figure. The scale bars correspond to $100 \mu \mathrm{m}$ in (A-D) and $50 \mu \mathrm{m}$ in (E-H). 


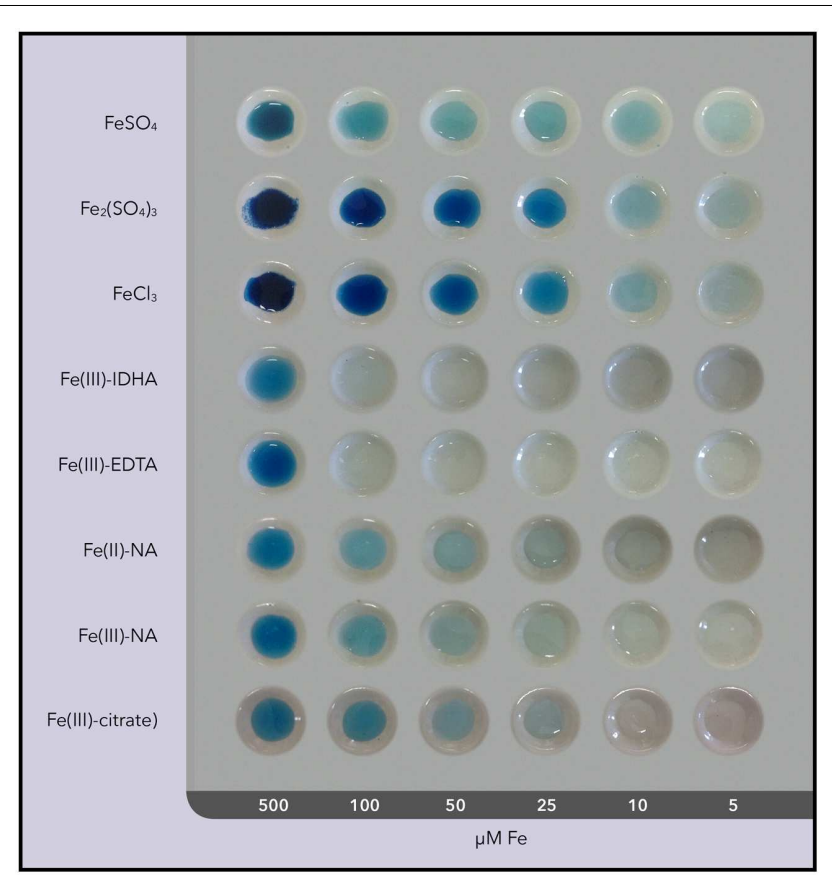

FIGURE 3 | Image of Perls blue stain with the different Fe compounds applied as foliar fertilizers and natural Fe compounds.

time after application. A blue color was observed in stomatal areas with some treatments but only in plants that were darkadapted (i.e., covered with a black plastic bag overnight), and then illuminated for a maximum of $30 \mathrm{~min}$ before foliar application. When plants were exposed to the growth chamber light for a longer period of time (i.e., $2 \mathrm{~h}$ or more), a Perls blue stain was observed in the vascular areas in some cases, but never in the stomatal areas with any of the treatments used. Unless otherwise stated, the observations described below refer to plants covered with a black plastic bag overnight and illuminated for only $30 \mathrm{~min}$.

At $30 \mathrm{~min}$ after fertilizer application, the Perls blue color appeared only in the stomata (red arrows), whereas no stain was observed in the mesophyll or vascular vessels with any of the Fe forms applied (Figures $4 \mathbf{A}-\mathbf{C}$ ). An exception was the $\mathrm{FeSO}_{4}+\mathrm{ABA}$ treatment, where no Perls blue color was observed anywhere (Figure 4D). When using a higher magnification, stomata appeared open and the blue Fe color was observed in the stomatal pore and/or the sub-stomatal cavity in all treatments (Figures 4E-G), with the exception of the plants pretreated with ABA (Figure $\mathbf{4 H}$ ). With regard to Fe(III)-EDTA, we did not observe any blue stain (data not shown). Chlorophyll fluorescence images of the same tissue preparations shown in Figures 4E-H reveal -in red- the location of the stomatal guard cells (GC) as well as the inner spongy mesophyll cells (SM) (Figures 4I-L). When plants were illuminated for $2 \mathrm{~h}$ or more prior to Fe fertilization, some stain appeared in the vascular areas (not shown), but the stain was never found in the stomatal areas.

At 60 min after fertilizer application, no Perls blue staining was observed in the main leaf vein (Figures 5A-E). However, in the case of the $\mathrm{FeSO}_{4}$ treatment some blue staining appeared in the minor leaf veins and the vascular bundles (red arrow in Figure 5F), whereas the stain was no longer present in the stomatal area (red square area in Figure 5F, see blowup in Figure 5P). Observing the minor veins with a higher magnification, it appears that the blue color is detected both in the phloem and xylem tissue, with the highest intensity being found in part of the phloem vessels (Figure 5K). In the case of $\mathrm{Fe}_{2}\left(\mathrm{SO}_{4}\right)_{3}$, we did not observe any changes from the image obtained at 30 min after Fe application, since the Perls blue stain still remained in the stomatal area (red square area in Figure 5G, see blow-up in Figure 5Q). A non-stained stomata is also seen in the purple square in Figure 5G. When Fe was applied as $\mathrm{FeCl}_{3}$, the blue color distribution was somewhat similar to that obtained with the other Fe(III) salt used, $\mathrm{Fe}_{2}\left(\mathrm{SO}_{4}\right)_{3}$ (Figures 5C,H,M,R), although the stain had moved slightly from the sub-stomatal cavity to neighboring spongy mesophyll cells (Figure 5R). With regard to Fe(III)-EDTA, we did not observe any blue stain (Figures 5D,I,N,S). Finally, when the plants were pre-treated with $\mathrm{ABA}$ before $\mathrm{FeSO}_{4}$ application we did not observe blue staining anywhere and stomata appeared closed (Figures 5E,J,O,T). When plants illuminated for $2 \mathrm{~h}$ or more were used with $\mathrm{FeSO}_{4}$, the blue stain was only found in vascular tissues (not shown).

At 90 min after fertilizer application, Perls blue staining was observed in the main vein in the case of $\mathrm{FeSO}_{4}$ (Figure 6A), with additional blue stain being found along the vascular tissues (Figure 6F). Using a higher magnification the stain appeared localized in the phloem tissue and also in some xylem areas (red square area in Figure 6A, see blow-up in Figure 6K). No stain was observed in the main vein with the other $\mathrm{Fe}$ compounds (Figures 7B-D). On the other hand, in the case of the Fe(III) salts the Perls blue stain did not change when compared to the $60 \mathrm{~min}$ image (Figures 6G,H). Non-stained stomata are also seen in the purple squares in Figures $\mathbf{6 G}, \mathbf{H}$. No blue stain was observed in plants treated with $\mathrm{Fe}$ (III)EDTA (Figures 6D,I,N) or pre-treated with $\mathrm{ABA}$ before $\mathrm{FeSO}_{4}$ application (Figures 6E,J,O).

After $24 \mathrm{~h}$, in the case of $\mathrm{FeSO}_{4}$ the Perls blue staining was localized in vascular tissues (red arrows in Figures 7A,E), with less staining in the central vein when compared to the $90 \mathrm{~min}$ images. In the case of $\mathrm{Fe}_{2}\left(\mathrm{SO}_{4}\right)_{3}$ the stain was present not only in stomatal areas but also in some areas of the vascular bundles (red arrows in Figure 7F), with no blue stain being observed inside the central vein (Figure 7B). In the case of $\mathrm{FeCl}_{3}$ the Perls blue stain was only present in the stomatal area (Figures 7C,G). Again, no blue stain was observed for Fe(III)-EDTA (Figures 7D,H).

\section{DISCUSSION}

Results show that the Perls blue staining method is useful for tracing the Fe uptake pathway in leaves, since it is capable to detect, using 70- $\mu \mathrm{m}$ leaf tissue sections, new labile Fe pools originated in the stomatal and vascular leaf areas after foliar fertilization. In vitro experiments indicate that the limit of detection can be as low as $5 \mu \mathrm{M}$ with Fe inorganic salts, 


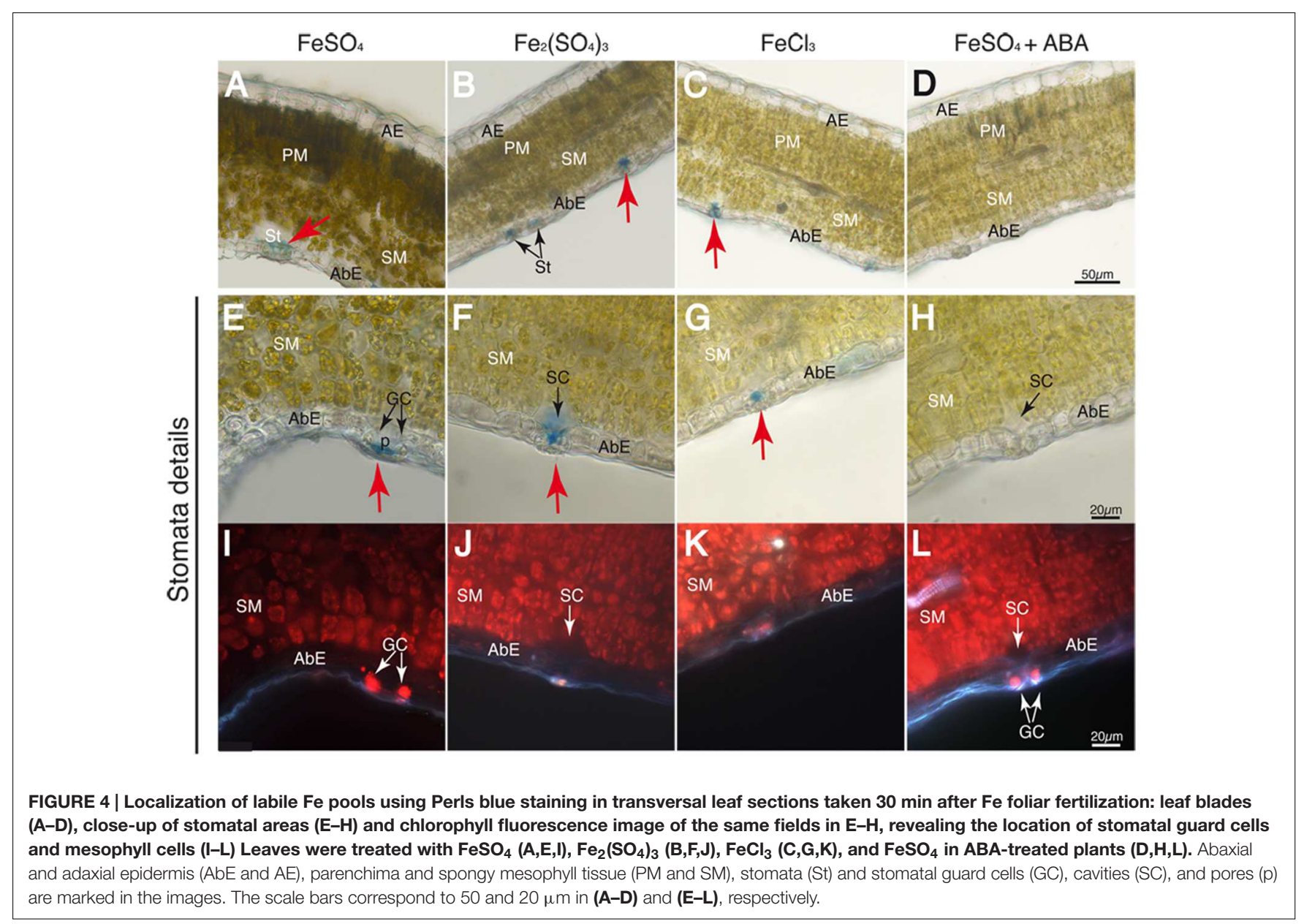

10-25 $\mu \mathrm{M}$ with Fe-complexes with natural, endogenous chelating agents such as NA and citrate and $100 \mu \mathrm{M}$ with synthetic Fechelates such as Fe(III)-EDTA and Fe(III)-IDHA. The detection of $\mathrm{Fe}$ in stomatal and vascular areas in leaves treated with $\mathrm{Fe}$ inorganic salts (both $\mathrm{Fe}$ (II) and $\mathrm{Fe}(\mathrm{III})$ ) supports that the new Fe labile pools occurring as a result of foliar Fe application of these compounds are in concentrations $>10 \mu \mathrm{M}$. However, since the Perls stain cannot provide information on Fe speciation, the detected new Fe pools may include either the original Fe species applied or in any of the natural Fe(II) or Fe(III) complexes that can be synthesized within the plant [e.g., Fe(II)-NA, Fe(III)-NA or Fe-citrate], given that all of them can be also detected with the Perls method at concentrations lower than $25 \mu \mathrm{M}$. In the case of fertilization with Fe(III)-EDTA, the lack of Perls stain supports that $\mathrm{Fe}$ concentrations $>100 \mu \mathrm{M}$ were not reached in any leaf area. The fact that Perls blue stain was never detected in the leaf mesophyll areas in the Fe-treated leaves is likely because labile Fe concentrations in this area are lower than $10 \mu \mathrm{M}$ (see below).

Results show that Fe applied as inorganic salts was taken up through the stomata, and that this occurred rapidly, within $30 \mathrm{~min}$ of the application. By this time leaf Fe concentrations had increased two to threefold (depending on the fertilizer) with $\mathrm{Fe}$ (II) in the form of sulfate, as well as with $\mathrm{Fe}$ (III) in the forms of sulfate and chloride. Conversely, in the case of
Fe(III)-EDTA an increase in leaf Fe occurred but no visible stains are evident (images not shown), as it could be expected from the poor limit of detection for this compound with the Perls method. The role of stomata in Fe uptake was confirmed using ABA, since ABA-induced stomatal closure fully inhibited Fe uptake, as shown both by the unchanged leaf Fe concentration and the absence of Perl blue stains in the images. These data also support that entrance though the cuticle did not occur, at least in plants pre-treated with ABA. These results confirm the previous observation that Fe uptake occurs via stomata (e.g., Middleton and Sanderson, 1965; Eichert et al., 1998, 2002; Schlegel and Schönherr, 2002; Fernández et al., 2005; Schlegel et al., 2005, 2006), and is in line with the suggestion that stomata could provide a pathway for Fe uptake from the leaf surface to the sub-stomatal cavity (Eichert and Burkhardt, 2001). Since the resolution of the images when using $70 \mu \mathrm{m}$-thick sections is limited, we cannot ascertain precisely whether the applied Fe entered leaves through mass flow or diffusion via wall surfaces.

There were major differences in Fe uptake among the inorganic $\mathrm{Fe}$ compounds tested, with $\mathrm{FeSO}_{4}$ being the most effective. The foliar application of $\mathrm{FeSO}_{4}$ led to a progressive appearance of the Perls blue stain, first in stomatal areas (at $30 \mathrm{~min}$ ), then in leaf blade vascular tissues (at $60 \mathrm{~min}$ ) and finally 


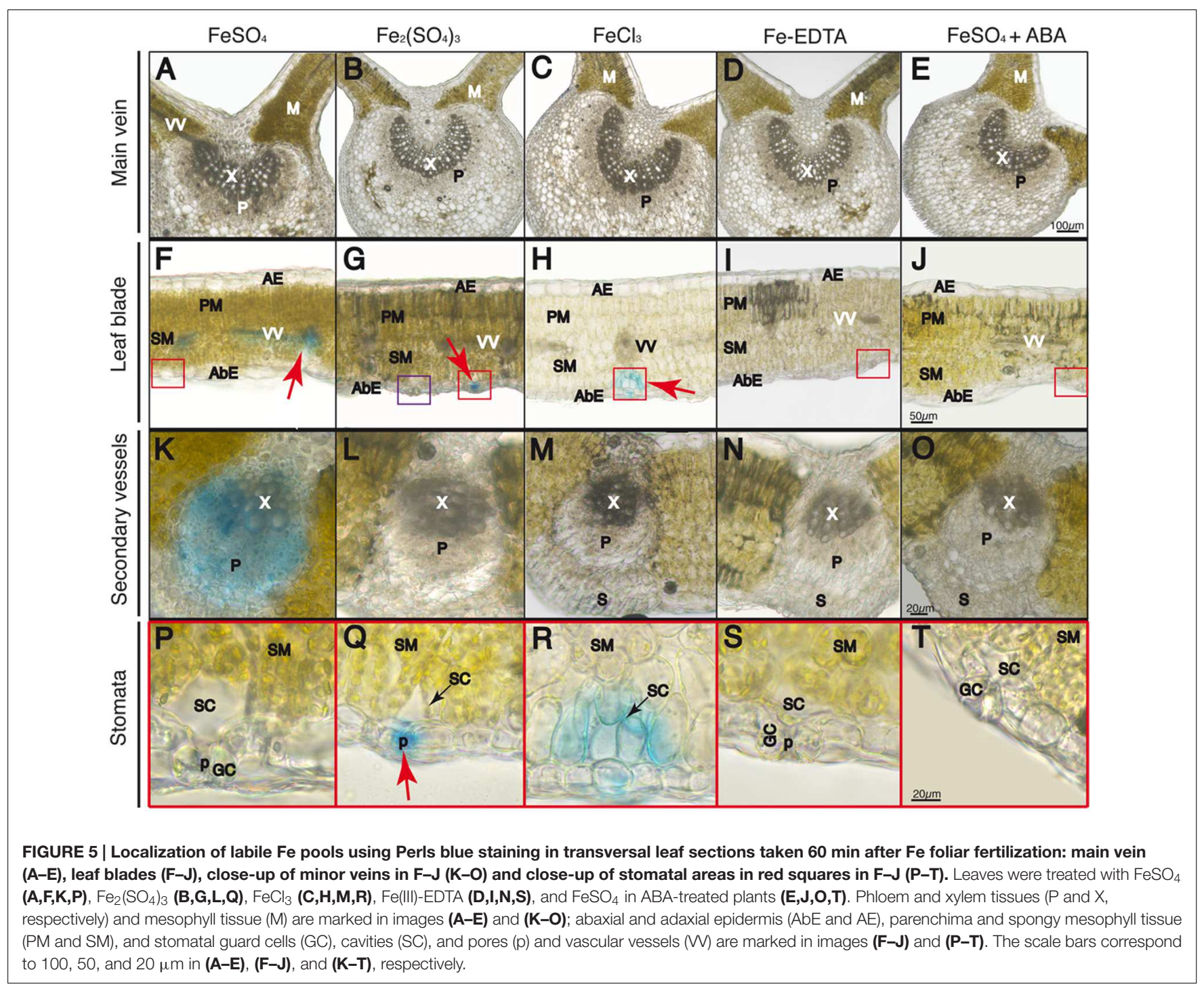

in the central vascular tissues (at $90 \mathrm{~min}$ ), with the initial Perls blue stain in the stomatal areas disappearing gradually. After 1 day, the stain in the central leaf vein had also faded, although the vascular tissues in the leaf vein were still stained. This pattern suggests the occurrence of labile (Perls-reacting) Fe pools in the stomatal areas that can be fully re-mobilized in less than $2 \mathrm{~h}$. This sequence of events was accompanied by twofold and 13\% increases (at 60 and $90 \mathrm{~min}$ ) and a 30\% decrease (at $24 \mathrm{~h}$ ) in leaf blade $\mathrm{Fe}$ concentration. After $24 \mathrm{~h}$, some Perls blue stain was still present in vascular tissues in the leaf blade, indicating the occurrence of some labile but non-mobile Fe pools in the vascular tissue. These results are in line with previous studies indicating that $\mathrm{FeSO}_{4}$ is a good foliar fertilizer (Rombolà et al., 2000; Pestana et al., 2001, 2003; Álvarez-Fernández et al., 2004; Fernández et al., 2006, 2008; Borowski, 2013). However, in the case of Fe(III) salts the Perls blue color was mostly restricted to the stomatal areas, although after $24 \mathrm{~h}$ some blue traces were also present in the vascular areas. The leaf Fe concentration increase with the two $\mathrm{Fe}(\mathrm{III})$ salts used was much lower than those with
$\mathrm{FeSO}_{4}$ in the short term, but afterward it increased progressively with time. This pattern suggests that the free Fe pools formed in stomata upon fertilization with Fe(III) salts were less mobile than those formed upon fertilization with $\mathrm{Fe}(\mathrm{II})$.

The differences found among the products tested could be potentially ascribed to the effects of ionic charge, molecular size and $\mathrm{pH}$ on the formation of Fe oxyhydroxides as Perlsreactive labile leaf Fe pools. Regarding charge, major ionic species in equilibrium at moderately acidic $\mathrm{pH}$ will be the +2 ion in the case of $\mathrm{Fe}(\mathrm{II})$ and +1 hydroxylated species in the case of $\mathrm{Fe}(\mathrm{III})$, respectively (Lindsay, 1995), whereas the -1 charged species will be prevalent in the case of Fe(III)-EDTA (Lindsay, 1979). Regarding molecular size, the mean maximum molecular radii of the Fe species likely to occur in the Fe formulations used are approximately $0.1 \mathrm{~nm}$ for $\mathrm{Fe}^{2+}$ and $<1 \mathrm{~nm}$ for $\mathrm{Fe}^{3+}$ hydroxylated species and $\mathrm{Fe}(\mathrm{III})$-EDTA (Fernández et al., 2008), sizes much smaller than the aperture of the stomata and below limits described for the transport of substances in the cuticle of a few species (ranging between 0.5 and $2.4 \mathrm{~nm}$; 


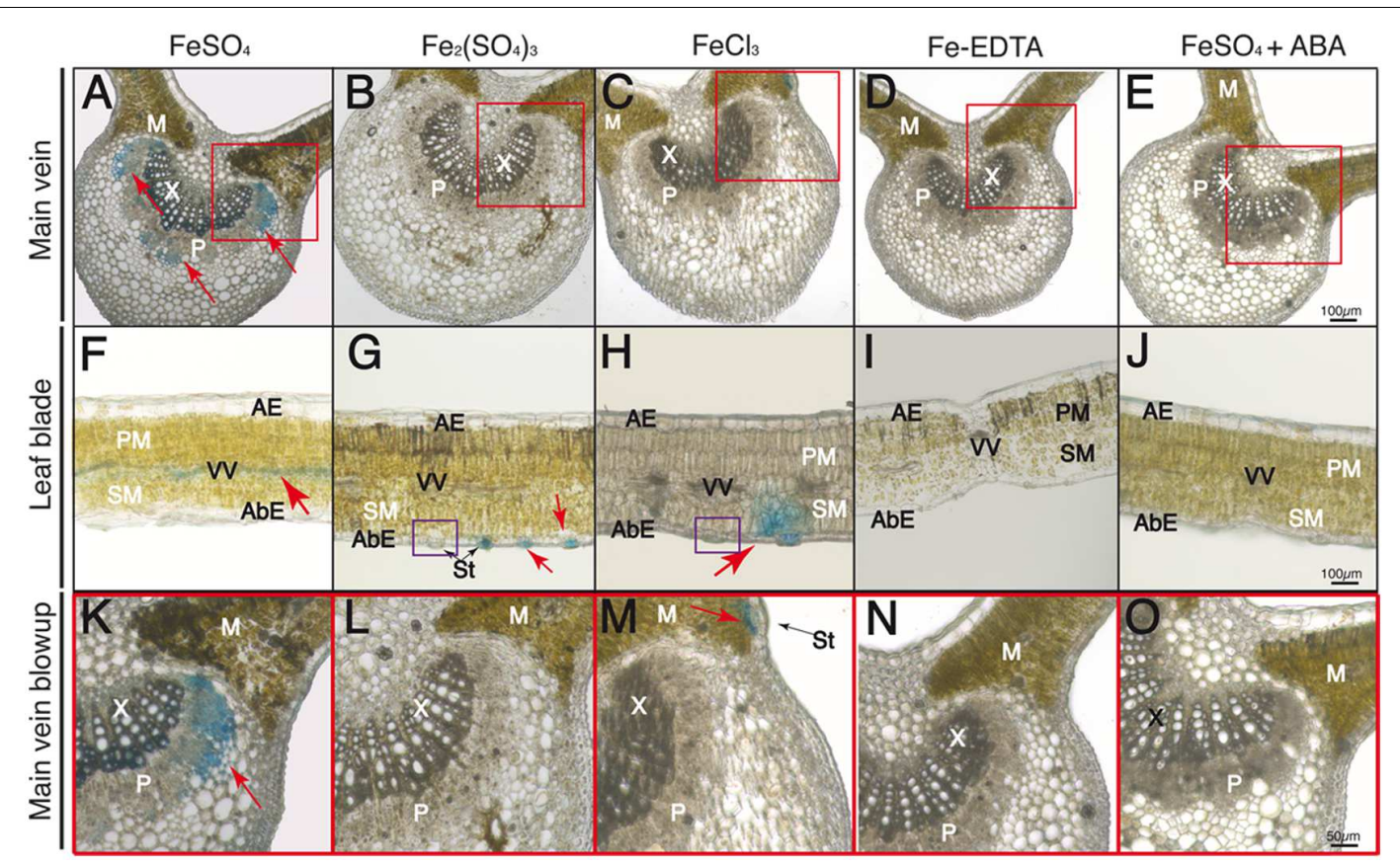

FIGURE 6 | Localization of labile Fe pools using Perls blue staining in transversal leaf sections taken 90 min after Fe foliar fertilization: main vein $(\mathbf{A}-\mathbf{E})$, leaf blades $(\mathbf{F}-\mathbf{J})$ and close-up of main vein areas in red squares in (A-E) (K-O). Leaves were treated with $\left.\mathrm{FeSO}_{4}(\mathbf{A}, \mathbf{F}, \mathbf{K}), \mathrm{Fe}_{2}(\mathrm{SO})_{3} \mathbf{( B}_{\mathbf{B}}, \mathbf{G}, \mathbf{L}\right), \mathrm{FeCl}_{3}$ $\mathbf{( C , H , M )}$, Fe(III)-EDTA (D,I,N) and $\mathrm{FeSO}_{4}$ in ABA-treated plants (E,J,O). Phloem and xylem tissues (P and X, respectively) and mesophyll tissue (M) are marked in images (A-E) and (K-O); abaxial and adaxial epidermis (AbE and AE), parenchima and spongy mesophyll tissue (PM and SM), stomata (St) and vascular vessels (W) are marked in images (F-J). Purple squares in $\mathbf{( G , H )}$ indicate stomata without blue stain. The scale bars correspond to 100 and 50 $\mu \mathbf{m}$ in $(\mathbf{A}-\mathbf{J})$ and $\mathbf{( K - O )}$, respectively.

Schönherr, 2006; Eichert and Goldbach, 2008). Regarding pH, a progressive appearance of oxyhydroxides would be expected, since Fe taken up must travel through a $\mathrm{pH}$ gradient, from the acidic fertilizer solutions $(\mathrm{pH} 3.9,3.2-3.3$, and 4.1 in the cases of $\mathrm{FeSO}_{4}, \mathrm{Fe}$ (III)salts and $\mathrm{Fe}$ (III)EDTA, respectively) toward the moderately acidic $\mathrm{pH}$ values generally prevalent in the leaf substomatal chamber (5.0; Felle and Hanstein, 2002), and the less acidic values in the apoplastic fluid (5.5-6.5 in sugar beet, LópezMillán et al., 2000; Larbi et al., 2010) and xylem sap (6.5-7.0 in peach, Larbi et al., 2003; 5.7-6.2 in sugar beet, López-Millán et al., 2000; Larbi et al., 2010).

Also, the presence in the different compartment of natural chelating agents such as NA and citrate as well as cell wall and plasma membrane interactions are likely to be relevant. In the case of the complexes with NA, the predominant ionic species will be the neutral molecule in the case of $\mathrm{Fe}$ (II)-NA and both the neutral molecule and +1 ion species in the case of $\mathrm{Fe}(\mathrm{III})$ NA (Rellán-Âlvarez et al., 2010). In the cases of the complexes with citrate, the predominant ionic species will be +2 ion species in the case of the $\mathrm{Fe}_{3}$-Citrate 3 and +2 and +1 species in the case of $\mathrm{Fe}_{2}$-Citrate 2 (Rellán-Álvarez et al., 2010). Concentrations reported so far are generally lower for NA [5-20 $\mu \mathrm{M}$ in tomato apoplastic fluid (Díaz-Benito, Unpublished Data) and 0-271 $\mu \mathrm{M}$ in the xylem sap of different species (Álvarez-Fernández et al., 2014)] than for citrate [0.2-1.8 $\mathrm{mM}$ in apoplastic fluid of different species (Álvarez-Fernández et al., 2014) and 0.1-0.8 mM in peach xylem sap (Larbi et al., 2003)]. A tentative explanation for the permanent Perls stain in stomata of leaves treated with Fe(III) can be inferred from in vitro citrate/NA ligand competition studies, which show that in the presence of citrate and at an acidic $\mathrm{pH}$ value (5.5) $\mathrm{Fe}$ (II)-NA can still occur whereas Fe(III)-NA would be absent due to the preferential formation of Fe-citrate complexes (Rellán-Álvarez et al., 2008). A possible hypothesis would be that $\mathrm{Fe}$ in the substomatal cavity can be transported more efficiently when $\mathrm{Fe}$ (II) is used because of the action of a so far uncharacterized Fe(II)-NA transporter. However, the complete lack of data for the citrate and NA concentrations in the substomatal cavity and the complexity of the Fe chemistry in aerobic environments (Pierre and Gautier-Luneau, 2000; Fernández and Ebert, 2005; Gautier-Luneau et al., 2005) do not allow to fully explain data found in this study.

Results show that in the conditions used in the experiment $(70 \% \mathrm{RH}) \mathrm{Fe}$ was taken up more efficiently when applied as Fe salts than when applied as Fe(III)-EDTA. This is likely due to the lower POD of Fe salts $(<60 \%$; Schönherr, 2002) when compared to those of Fe(III)-EDTA (near 100\% RH) (Schönherr et al., 2005). At humidity values of $70 \%$ or lower (values similar to those commonly found in field conditions in areas affected by $\mathrm{Fe}$ chlorosis) the uptake of Fe from any compound with high POD values will be limited only to the periods when they are present in liquid form (i.e., immediately after application and before fertilizer drying), whereas in the case of Fe salts the lower POD will allow for a more extended uptake period. Although it has been proposed that once in the apoplast non-charged Fe forms 


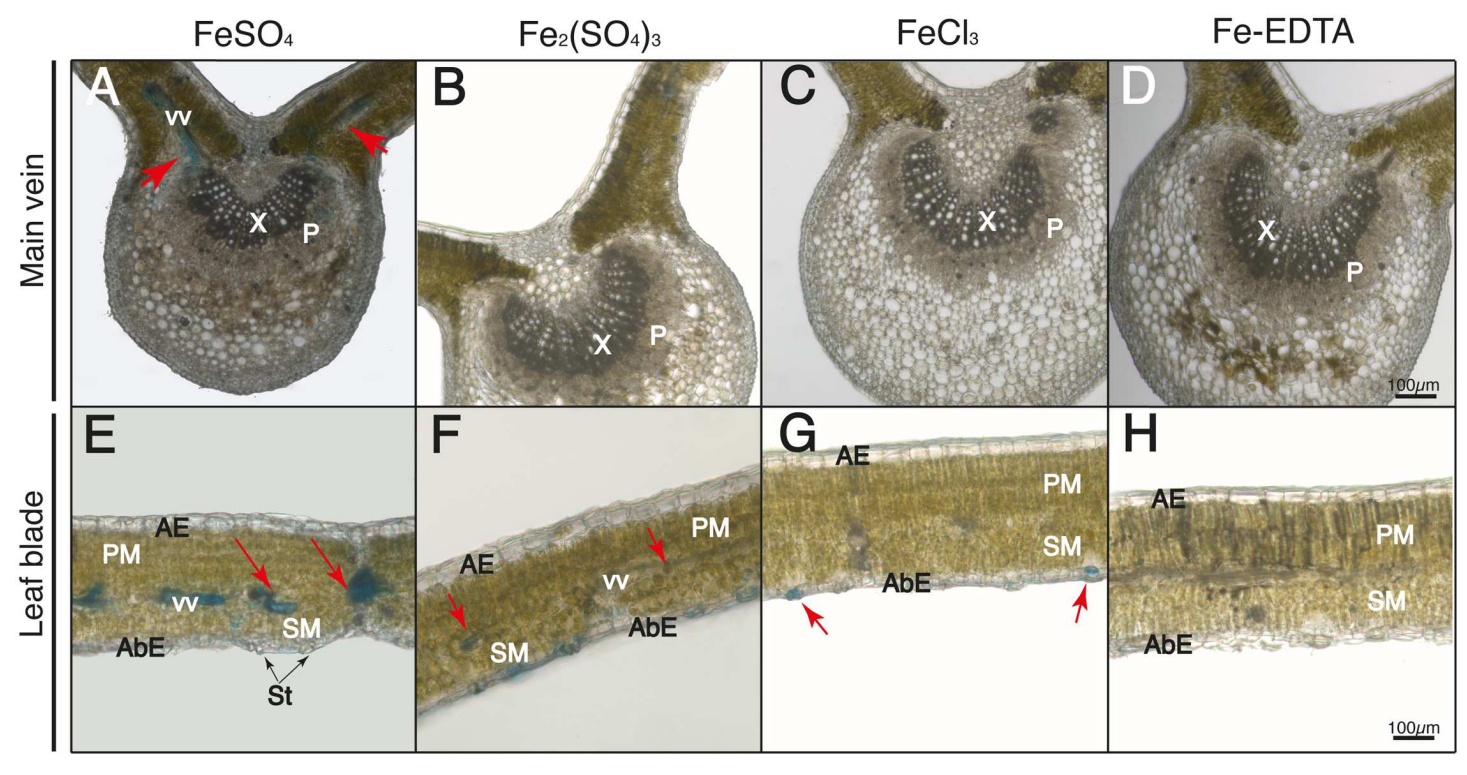

FIGURE 7 | Localization of labile Fe pools using Perls blue staining in transversal leaf sections taken $24 \mathrm{~h}$ after Fe foliar fertilization: main vein (A-D) and leaf blades (E-H) Leaves were treated with $\mathrm{FeSO}_{4}(\mathbf{A}, \mathbf{E}), \mathrm{Fe}_{2}\left(\mathbf{S O}_{4}\right)_{3}(\mathbf{B}, \mathbf{F}), \mathrm{FeCl}_{3}(\mathbf{C}, \mathbf{G})$, and $\mathrm{Fe}(\mathrm{III})$-EDTA (D,H). Phloem and xylem tissues (P and X, respectively) and vascular vessels (M) are marked in images (A-D); abaxial and adaxial epidermis (AbE and AE), parenchima and spongy mesophyll tissue (PM and SM), stomata (St) and vascular vessels (M) are marked in images (E-H). Scale bars correspond to $100 \mu \mathrm{m}$.

could be translocated in the apoplast more easily than positively charged ones (Fernández et al., 2005), our data show that Fe ionic forms are easily taken up and translocated, perhaps after conversion into neutral forms. Therefore, the view that foliarapplied chelates such as Fe(III)-EDTA could be translocated more readily than ionic Fe-containing substances (Hsu and Ashmead, 1984; Fernández et al., 2005) should be taken with caution.

Results showing a rapid intra-leaf mobility of $\mathrm{Fe}$ in foliar fertilized leaves are in contrast with the widely accepted view that foliar Fe fertilization has only local effects in the foliage directly treated (Zhang and Brown, 1999; Fernández et al., 2013; El-Jendoubi et al., 2014) due to the poor Fe mobility into other plant organs (White, 2012). These apparently contrasting results can be reconciled by two reasons. First, intra-leaf mobility can be overestimated with the regular non-enhanced Perls method, because the Fe-deficient mesophyll tissue can take up avidly Fe upon fertilization, leading to free Fe concentrations in the bulk mesophyll below the $5 \mu \mathrm{M}$ detection range. This is confirmed by the fact that when the more sensitive Perls diaminobenzidineenhanced method (Perls-DAB) was used in $\mathrm{FeSO}_{4}$-treated leaves the whole leaf mesophyll tissue was stained (El-Jendoubi et al., 2014). Second, there is new evidence for Fe long distance mobility after foliar fertilization, although this may be species-dependent. Recent studies have shown that some of the Fe taken up by leaves, $1-12 \%$ depending on the fertilizer and the plant species, can move from the treated leaves toward the roots (Nikolic et al., 2003; Rodríguez-Lucena et al., 2009, 2010; Roosta and Mohsenian, 2012; Zhang et al., 2013; Carrasco-Gil et al., 2016). In tomato, it has been proposed that this occurs via phloem transport, since phloem tissues are stained by Perls blue shortly after foliar fertilization (Carrasco-Gil et al., 2016).
An interesting issue is why no Perls blue stain is visible in the stomatal areas when $\mathrm{FeSO}_{4}$ was applied to plants illuminated for $2 \mathrm{~h}$ or more. A likely explanation is that in Fe-deficient plants light-adapted for $2 \mathrm{~h}$ or more the uptake and/or transport processes could be primed and thereby be faster than in leaves coming from a prolonged dark period. This priming would lead to a faster Fe uptake into cells and organelles and transport, so that no labile (Perls-detectable) Fe pools would occur in the stomatal areas. The existence of this priming effect is supported by the fact that increases in leaf Fe concentration 30 min after foliar treatment were larger in leaves light-adapted for $2 \mathrm{~h}$ than in those coming from dark adaptation (31 vs. $20 \mu \mathrm{g} \mathrm{Fe} \mathrm{g}^{-1}$ DW). Furthermore, at 60 and $90 \mathrm{~min}$, the leaf Fe concentrations became similar in both plant types, whereas after 1 day the leaf Fe concentration was lower in plants treated after light-adaptation than in those treated after dark-adaptation.

In summary, we have shown that the Perls blue method is a good tool to trace the Fe uptake pathway in leaves when using Fe salts, but is not sensitive enough when using synthetic $\mathrm{Fe}$ (III)-chelates such as $\mathrm{Fe}(\mathrm{III})$-EDTA or $\mathrm{Fe}$ (III)-IDHA. Foliar $\mathrm{Fe}$ fertilization increased leaf $\mathrm{Fe}$ concentrations with all $\mathrm{Fe}$ compounds used, with inorganic Fe salts being more efficient than Fe(III)-EDTA. Results show that Fe applied as inorganic salts was taken up rapidly through the stomata. In the case of using $\mathrm{FeSO}_{4}$ a progression of the stain was seen with time toward vascular areas in the leaf blade and the central vein, whereas in the case of $\mathrm{Fe}(\mathrm{III})$ salts the stain remained in the stomatal areas. The Perls method is cheap and accessible in many research and industrial laboratories and does not require expensive, dedicated instrumentation as it occurs for other metal image analysis techniques. Results in this study open the possibility to easily test 
new Fe fertilizer formulations, as well as to study the possible Fe transporters responsible for leaf Fe uptake.

\section{AUTHOR CONTRIBUTIONS}

JR and SC-G carried out experiments, JR, SC-G, AA, and JA planned research, JR and JA wrote the paper.

\section{FUNDING}

Study supported by the Spanish Ministry of Science and Competitivity (MINECO; projects IPT-2012-0004-060000,

\section{REFERENCES}

Abadía, J., López-Millán, A. F., Rombolá, A. D., and Abadía, A. (2002). Organic acids and Fe deficiency: a review. Plant Soil 241, 75-86. doi: 10.1023/A:1016093317898

Abadía, J., Vázquez, S., Rellán-Álvarez, R., El-Jendoubi, H., Abadía, A., Álvarez-Fernández, A., et al. (2011). Towards a knowledge-based correction of iron chlorosis. Plant Physiol. Biochem. 49, 471-482. doi: 10.1016/j.plaphy.2011.01.026

Álvarez-Fernández, A., Díaz-Benito, P., Abadía, A., López-Millán, A. F., and Abadía, J. (2014). Metal species involved in long distance metal transport in plants. Front. Plant Sci. 5:105. doi: 10.3389/fpls.2014. 00105

Álvarez-Fernández, A., García-Laviña, P., Fidalgo, C., Abadía, J., and Abadía, A. (2004). Foliar fertilization to control iron chlorosis in pear trees. Plant Soil 263, 5-15. doi: 10.1023/B:PLSO.0000047717.97167.d4

Basiouny, F. M., and Biggs, R. H. (1976). Penetration of 57Fe through isolated cuticles of citrus leaves. HortScience 11, 417-419.

Borowski, E. (2013). Uptake and transport of iron ions $(\mathrm{Fe}+2, \mathrm{Fe}+3)$ supplied to roots or leaves in spinach (Spinacia oleracea L.) plants growing under different light conditions. Acta Agrobot. 66, 45-62. doi: 10.5586/aa.2013. 021

Briat, J. F., Dubos, C., and Gaymard, F. (2015). Iron nutrition, biomass production, and plant product quality. Trends Plant Sci. 20, 33-40. doi: 10.1016/j.tplants.2014.07.005

Burkhardt, J., Kaiser, H., Goldbach, H., and Kappen, L. (1999). Measurements of electrical leaf surface conductance reveal re-condensation of transpired water vapour on leaf surfaces. Plant Cell Environ. 22, 189-196. doi: 10.1046/j.13653040.1999.00387.x

Carrasco-Gil, S., Rios, J. J., Álvarez-Fernández, A., Abadía, A., García-Mina, J. M., and Abadía, J. (2016). Effects of individual and combined metal foliar fertilization on iron- and manganese-deficient Solanum lycopersicum plants. Plant Soil 402, 27-45. doi: 10.1007/s11104-016-2806-4

Chamel, A., Escoubes, M., Baudrand, G., and Girard, G. (1992). Determination of water sorption by cuticles isolated from fir tree needles. Trees 6, 109-114. doi: 10.1007/BF00226589

Chamel, A., Pineri, M., and Escoubes, M. (1991). Quantitative determination of water sorption by plant cuticles. Plant Cell Environ. 14, 87-95. doi: 10.1016/j.scitotenv.2014.06.119

Dybing, C. D., and Currier, H. B. (1961). Foliar penetration by chemicals. Plant Physiol. 36, 169-174. doi: 10.1104/pp.36.2.169

Eichert, T., and Burkhardt, J. (2001). Quantification of stomatal uptake of ionic solutes using a new model system. J. Exp. Bot. 52, 771-781.

Eichert, T., Burkhardt, J., and Goldbach, H. E. (2002). Some factors controlling stomatal uptake. Acta Hortic. 594, 85-90. doi: 10.17660/ActaHortic.2002. 594.6

Eichert, T., and Goldbach, H. E. (2008). Equivalent pore radii of hydrophilic foliar uptake routes in stomatous and astomatous leaf surfaces-further evidence for a stomatal pathway. Physiol. Plant. 132, 491-502. doi: 10.1111/j.13993054.2007.01023.x
AGL2012-31988, and AGL2013-31988, co-financed with the European Regional Development Fund) and the Aragón Government (group A03). JR. was supported by a JAE-Doc (CSIC) grant.

\section{ACKNOWLEDGMENTS}

Authors thank Aurora Poc for laboratory help, Ana ÁlvarezFernández for helpful discussions and Ernesto Igartua for advice in statistical analysis. This paper is dedicated to the memory of Luis Heras and Manuel Sanz, pioneers in the study of fruit tree nutrition and fertilization at the EEAD-CSIC.

Eichert, T., Goldbach, H. E., and Burkhardt, J. (1998). Evidence for the uptake of large anions through stomatal pores. Bot. Acta 111, 461-466. doi: 10.1111/j.1399-3054.2008.01135.x

Eichert, T., Kurtz, A., Steiner, U., and Goldbach, H. E. (2008). Size exclusion limits and lateral heterogeneity of the uptake pathway for aqueous solutes and watersuspended nanoparticles. Physiol. Plant. 134, 151-160. doi: 10.1111/j.13993054.2008.01135.x

Eiden, R., Burkhardt, J., and Burkhardt, O. (1994). Atmospheric particles and their role in the information of dew on the surface of plant leaves. J. Aerosol Sci. 25, 367-376. doi: 10.1016/0021-8502(94)90087-6

El-Jendoubi, H., Melgar, J. C., Álvarez-Fernández, A., Sanz, M., Abadía, A., and Abadía, J. (2011). Setting good practices to assess the efficiency of iron fertilizers. Plant Physiol. Biochem. 49, 483-488. doi: 10.1016/j.plaphy.2011. 02.013

El-Jendoubi, H., Vázquez, S., Calatayud, A., Vavpetič, P., Vogel-Mikuš, K., Pelicon, P., et al. (2014). The effects of foliar fertilization with iron sulfate in chlorotic leaves are limited to the treated area. A study with peach trees (Prunus persica L. Batsch) grown in the field and sugar beet (Beta vulgaris L.) grown in hydroponics. Front. Plant Sci. 5:2. doi: 10.3389/fpls.2014. 00002

Felle, H. H., and Hanstein, S. (2002). The apoplastic pH of the substomatal cavity of Vicia faba leaves and its regulation responding to different stress factors. J. Exp. Bot. 53, 73-82. doi: 10.1093/jexbot/53.366.73

Fernández, V., and Brown, P. H. (2013). From plant surface to plant metabolism: the uncertain fate of foliar applied nutrients. Front. Plant Sci. 4:289. doi: 10.3389/fpls.2013.00289

Fernández, V., del Rio, V., Abadía, J., and Abadía, A. (2006). Foliar iron fertilization of peach (Prunus persica L. Batsch): effects of iron compounds, surfactants and other adjuvants. Plant Soil 289, 239-252. doi: 10.3389/fpls.2014.00002

Fernández, V., del Rio, V., Pumariño, L., Igartua, E., Abadía, J., and Abadía, A. (2008). Foliar fertilization of peach (Prunus persica L. Batsch) with different iron formulations: effects on re-greening, iron concentration and mineral composition in treated and untreated leaf surfaces. Sci. Hortic. 117, 241-248. doi: $10.3389 /$ fpls.2014.00002

Fernández, V., and Ebert, G. (2005). Foliar iron fertilization: a critical review. J. Plant Nutr. 28, 2113-2124. doi: 10.1080/01904160500320954

Fernández, V., Ebert, G., and Winkelmann, G. (2005). The use of microbial siderophores for foliar application studies. Plant Soil 272, 245-252. doi: 10.1007/s11104-004-5212-2

Fernández, V., and Eichert, T. (2009). Uptake of hydrophilic solutes through plant leaves: current state of knowledge and perspectives of foliar fertilization. Crit. Rev. Plant Sci. 28, 36-68. doi: 10.1080/07352680902743069

Fernández, V., Guzmán-Delgado, P., Garça, J., Santos, S., and Gil, L. (2016). Cuticle structure in relation to chemical composition: re-assessing the prevailing model. Front. Plant Sci. 7:427. doi: 10.3389/fpls.2016.00427

Fernández, V., Sotiropoulos, T., and Brown, P. H. (2013). Foliar Fertilization. Scientific Principles and Field Practices. Paris: International Fertilizer Industry Association.

Gautier-Luneau, I., Merle, C., Phanon, D., Lebrun, C., Biaso, F., Serratrice, G., et al. (2005). New trends in the chemistry of iron(III) citrate complexes: correlations 
between X- ray structures and solution species probed by electrospray mass spectrometry and kinetics of iron uptake from citrate by iron chelators. Chem. Eur. J. 11, 2207-2219. doi: 10.1002/chem.200401087

Greenne, D. W., and Bukovac, M. J. (1971). Factors influencing the penetration of naphthaleneacetamide into leaves of pear (Pyrus communis L.). J. Am. Soc. Hortic. Sci. 96, 240-246.

Gruda, N. (2005). Impact of environmental factors on product quality of greenhouse vegetables for fresh consumption. Crit. Rev. Plant Sci. 24, 227-247. doi: 10.1080/07352680591008628

Hsu, H. H., and Ashmead, H. D. (1984). Effect of urea and ammonium nitrate in the uptake of iron through leaves. J. Plant Nutr. 7, 291-299. doi: $10.1080 / 01904168409363196$

Jordan, G. J., and Brodribb, T. J. (2007). Incontinence in aging leaves: deteriorating water relations with leaf age in Agastachys odorata R. Br. (Proteaceae), a shrub with very long-lived leaves. Funct. Plant Biol. 34, 918-924.

Kannan, S. (1969). Penetration of iron and some organic substances through isolated cuticulae membranes. Plant Physiol. 44, 517-521. doi: 10.1104/pp.44.4.517

Koch, K., and Ensikat, H. J. (2008). The hydrophobic coating of plant surfaces: epicuticular wax crystals and their morphologies, crystallinity and molecular self-assembly. Micron 39, 759-772. doi: 10.1016/j.micron.2007.11.010

Larbi, A., Morales, F., Abadía, A., and Abadía, J. (2010). Changes in iron and organic acid concentrations in xylem sap and apoplastic fluid of iron-deficient Beta vulgaris plants in response to iron resupply. J. Plant Physiol. 167, 255-260. doi: 10.1016/j.jplph.2009.09.007

Larbi, A., Morales, F., Abadía, J., and Abadía, A. (2003). Effects of branch solid Fe sulphate implants on xylem sap composition in field-grown peach and pear: changes in Fe, organic anions and pH. J. Plant Physiol. 160, 1473-1481. doi: 10.1078/0176-1617-01010

Lindsay, W. L. (1979). Chemical Equilibria in Soils. New York, NY: WileyInterscience, 449.

Lindsay, W. L. (1995). "Chemical reactions in soils that affect iron availability to plants: a quantitative approach," in Iron Nutrition in Soils and Plants, ed. J. Abadía (Dordrecht: Kluwer Academic Publishers), 7-14.

López-Millán, A.-F., Morales, F., Abadía, A., and Abadía, J. (2000). Effects of iron deficiency on the composition of the leaf apoplastic fluid and xylem sap in sugar beet. Implications for iron and carbon transport. Plant Physiol 124, 873-884. doi: 10.1104/pp.124.2.873

Middleton, L. J., and Sanderson, J. (1965). Uptake of inorganic ions by plant leaves. J. Exp. Bot. 16:169. doi: 10.1093/jxb/16.2.197

Munné-Bosch, S. (2007). Aging in Perennials. Crit. Rev. Plant Sci. 26, 123-138. doi: 10.1080/07352680701402487

Nikolic, M., Cesco, S., Römheld, V., Varanini, Z., and Pinton, R. (2003). Uptake of iron $(59 \mathrm{Fe})$ complexed to water-extractable humic substances by sunflower leaves. J. Plant Nutr. 26, 2243-2252. doi: 10.1186/s12864-0152331-5

Outlaw, R. H. (2003). Integration of cellular and physiological functions of guard cells. Crit. Rev. Plant Sci. 22, 503-529. doi: 10.1080/7136 08316

Pestana, M., Correia, P. J., Varannes, A., Abadía, J., and Faria, E. A. (2001). Effectiveness of different foliar iron applications to control iron chlorosis in orange trees grown on a calcareous soil. J. Plant Nutr. 24, 613-622. doi: 10.1081/PLN-100103656

Pestana, M., de Varennes, A., and Faria, E. A. (2003). Diagnosis and correction of iron chlorosis in fruit tress: a review. Food Agric. Environ. 1, 46-51.

Pierre, J. L., and Gautier-Luneau, I. (2000). Iron and citric acid: a fuzzy chemistry of ubiquitous biological relevance. Biometals 13, 91-96. doi: 10.1023/A:1009225701332

Ramsey, R. J. L., Stephenson, S. G. R., and Hall, H. C. (2005). A review of the effect of humidity, humectants, and surfactnant composition on the absorption and efficacy of highly water-soluble herbicide. Pestic. Biochem. Physiol. 82, 162-175. doi: 10.1016/j.pestbp.2005.02.005

Rellán-Álvarez, R., Abadía, J., and Álvarez-Fernández, A. (2008). Formation of metal-nicotianamine complexes as affected by $\mathrm{pH}$, ligand exchange with citrate and metal exchange. A study by electrospray ionization time-of-flight mass spectrometry. Rapid Commun. Mass Spectrom. 22, 1553-1562. doi: $10.1002 / \mathrm{rcm} .3523$
Rellán-Álvarez, R., Giner-Martínez-Sierra, J., Orduna, J., Orera, I., RodríguezCastrillón, J. A., García-Alonso, J. I., et al. (2010). Identification of a triIron(III), tri-citrate complex in the xylem sap of iron-deficient tomato resupplied with iron: new insights into plant iron long-distance transport. Plant Cell Physiol. 51, 91-102. doi: 10.1093/pcp/pcp170

Rodríguez-Lucena, P., Hernández-Apaolaza, L., and Lucena, J. J. (2010). Comparison of iron chelates and complexes supplied as foliar sprays and in nutrient solution to correct iron chlorosis of soybean. J. Plant Nutr. Soil Sci. 173, 120-126. doi: 10.1002/jpln.200800256

Rodríguez-Lucena, P., Tomasi, N., Pinton, R., Hernández-Apaolaza, L., Lucena, J. J., and Cesco, S. (2009). Evaluation of 59Fe-lignosulfonate complexes as $\mathrm{Fe}$ sources for plants. Plant Soil 325, 53-63. doi: 10.1007/s11104-009-0091-1

Rombolà, A. D., Bruggemann, W., Tagliavini, M., Marangoni, B., and Moog, P. R. (2000). Iron source affect iron reduction and re-greeening of kiwifruit leaves. J. Plant Nutr. 23, 1751-1765. doi: 10.1080/01904160009382139

Roosta, H. R., and Mohsenian, Y. (2012). Effects of foliar spray of different Fe sources on pepper (Capsicum annum L.) plants in aquaponic system. Sci. Hortic. 146, 182-191. doi: 10.1016/j.scienta.2012.08.018

Roschzttardtz, H., Conéjéro, G., Curie, C., and Mari, S. (2009). Identification of the endodermal vacuole as the iron storage compartment in the Arabidopsis embryo. Plant Phisiol. 151, 1329-1338. doi: 10.1104/pp.109.144444

Roschzttardtz, H., Conéjéro, G., Curie, C., and Mari, S. (2010). Straightforward histochemical staining of $\mathrm{Fe}$ by the adaptation of an old-school technique: identification of the endodermal vacuole as the site of Fe storage in Arabidopsis embryos. Plant Signal. Behav. 5, 56-57. doi: 10.4161/psb.5.1.10159

Schlegel, T., Schönherr, J., and Schreiber, L. (2005). Size selectivity of aqueous pores in stomatous cuticles of Vicia faba leaves. Planta 221, 648-655. doi: 10.1007/s00425-005-1480-1

Schlegel, T., Schönherr, J., and Schreiber, L. (2006). Rate of foliar penetration of chelated Fe(III): role of light, stomata, species, and leaf age. J. Agric. Food Chem. 54, 6809-6813. doi: 10.1021/jf061149i

Schlegel, T. K., and Schönherr, J. (2002). Stage of development affects penetration of calcium chloride into apple fruits. J. Plant Nutr. Soil Sci. 165, 738-745. doi: 10.1002/jpln.200290012

Schönherr, J. (2000). Calcium chloride penetrates plant cuticles via aqueous pores. Planta 212, 112-118. doi: 10.1007/s004250000373

Schönherr, J. (2001). Cuticular penetration of calcium salts: effect of humidity, anions, and adjuvants. J. Plant Nutr. Soil Sci. 164, 225-231. doi: 10.1002/15222624(200104)164:2<225::AID-JPLN225>3.3.CO;2-E

Schönherr, J. (2002). A mechanistic analysis of penetration of glyphosate salts across astomatous cuticular membranes. Pest. Manag. Sci. 58, 343-351. doi: $10.1002 /$ ps.462

Schönherr, J. (2006). Characterization of aqueous pores in plant cuticles and permeation of ionic solutes. J. Exp. Bot. 57, 2471-2491. doi: 10.1093/jxb/erj217

Schönherr, J., and Bukovac, M. J. (1972). Penetration of stomata by liquids. Dependence of surfaces tension, wettability, and stomatal morphology. Plant Physiol. 49, 813-819. doi: 10.1104/pp.49. 5.813

Schönherr, J., and Bukovac, M. J. (1978). Foliar penetration of succinic acid2,2-dimethylhydrazide: mechanisms and rate limiting step. Physiol. Plant. 42, 243-251. doi: 10.1111/j.1399-3054.1978.tb02555.x

Schönherr, J., Fernández, V., and Schreiber, L. (2005). Rates of cuticular penetration of chelated $\mathrm{Fe}(\mathrm{III})$ : role of humidity, concentration, adjuvants, temperature, and type of chelate. J. Agric. Food Chem. 53, 4484-4492. doi: $10.1021 /$ jf050453t

Schönherr, J., and Luber, M. (2001). Cuticular penetration of potassium salts: effects of humidity, anions and temperature. Plant Soil 236, 117-122. doi: 10.1023/A:1011976727078

Schönherr, J., and Riederer, M. (1986). Plant cuticles sorb lipophilic compounds during enzymatic isolation. Plant Cell Environ. 9, 459-466. doi: 10.1111/j.13653040.1986.tb01761.x

Schönherr, J., and Schreiber, L. (2004). Size selectivity of aqueous pores in astomatous cuticular membranes isolated from Populus canescens (aiton) sm. leaves. Planta 219, 405-411.

Strugger, S. (1939). Die lumineszenzmikroskopische analyse des transpitionsstromes in parenchymen. 3. Untersuchungen an Helxine Soleorolii. Req. Biol. Zentralbl. 59, 409-442. 
Terry, N., and Abadía, J. (1986). Function of iron in chloroplasts. J. Plant Nutr. 9, 609-646. doi: 10.1080/01904168609363470

White, P. J. (2012). "Long-distance transport in the xylem and phloem," in Mineral Nutrition of Higher Plants, ed. P. Marschner (San Diego, CA: Academic Press), 49-70.

Zhang, H., Yang, H., Wang, Y., Gao, Y., and Zhang, L. (2013). The response of ginseng grown on farmland to foliar-applied iron, zinc, manganese and copper. Ind. Crop. Prod. 45, 388-394. doi: 10.1016/j.indcrop.2012.12.047

Zhang, Q. L., and Brown, P. H. (1999). The mechanism of foliar zinc absorption in pistachio and walnut. J. Am. Soc. Hortic. Sci. 124, 312-317.
Conflict of Interest Statement: The authors declare that the research was conducted in the absence of any commercial or financial relationships that could be construed as a potential conflict of interest.

Copyright (๑) 2016 Rios, Carrasco-Gil, Abadía and Abadía. This is an open-access article distributed under the terms of the Creative Commons Attribution License (CC BY). The use, distribution or reproduction in other forums is permitted, provided the original author(s) or licensor are credited and that the original publication in this journal is cited, in accordance with accepted academic practice. No use, distribution or reproduction is permitted which does not comply with these terms. 